\title{
Beta-blockers in bronchial asthma: effect of propranolol and pindolol on large and small airways
}

\author{
D PATAKAS, V ARGIROPOULOU, G LOURIDAS, V TSARA \\ From the Pulmonary Clinic, School of Medicine, Aristotelion University of Thessaloniki, Greece
}

ABSTRACT In 11 asthmatic subjects the relative magnitude and the site of airway bronchoconstr-位 iction were compared after the oral administration of $40 \mathrm{mg}$ of propranolol and $2.5 \mathrm{mg}$ of pindolol and the magnitude and site of bronchodilation produced by $0.5 \mathrm{mg}$ subcutaneous ter- $-\infty$ butaline were tested after pretreatment with propranolol and pindolol. Specific airway conduc-o tance (sGaw) and peak expiratory flow rate (PEFR), both believed to reflect changes in largeairways, and capacity isoflow (Ciso- $\dot{v}$ ) and $\Delta \dot{V} \max _{\mathbf{s 0}}$, both believed to reflect changes in small $\mathbb{D}^{\mathrm{T}}$ airways, were determined before and after administration of placebo, pindolol, and propranolol.을 Treatments were given double blind and in random order. After the administration of prop ranolol we noted a significant bronchoconstrictive effect in the large airways (mean values of PEFR and sGaw, expressed as percentages of control values, decreased by $87.4 \% \pm 13.2 \%$ anc\% $43.3 \% \pm 8.9 \%$ ) and in the small airways (mean value of Ciso-i increased by $20.6 \% \pm 4.7 \%$ and that of $\Delta \dot{V} \max _{50}$ decreased by $50 \% \pm 11.9 \%$ of control). By contrast, pindolol produced noo significant effect on sGaw or PEFR but the tests of small airway function showed significants bronchoconstriction (mean values of Ciso- $\dot{v}$ increased by $12.9 \% \pm 2.6 \%$ and those of $\Delta \dot{V} \max _{500}$ decreased by $47.2 \% \pm 9 \cdot 2 \%$ ). This action makes pindolol potentially dangerous in asthmatico patients. The bronchodilator action of terbutaline on large airways is diminished after the use of $\overrightarrow{\vec{B}}$ both propranolol and pindolol.

Information on the effects of $\beta$-adrenergic blocking drugs on respiratory function tests in asthmatic subjects has been reported, ${ }^{1-3}$ but so far little information is available on the effects of $\beta$-adrenergic blocking drugs on the results of tests believed to reflect small airway function.

Bronchodilation is mediated through catecholamine stimulation of the $\beta_{2}$-receptors in the lung and $\beta$-adrenergic-blocking drugs can precipitate bronchoconstriction. It is generally believed that intrinsic sympathetic activity is desirable in a betablocker that has to be given to a patient prone to bronchoconstriction. ${ }^{45}$ Non-selective $\beta$-adrenergic blockers, with or without intrinsic sympathetic activity, may lessen the bronchodilator effect of $\beta_{2-}$ stimulants. ${ }^{6}$

This study was designed to compare the effects of oral propranolol (a drug with practically no intrinsic sympathetic activity) and pindolol (a drug with high intrinsic sympathetic activity) on large and small airways and to examine the bronchodilator effect of

Address for reprint requests: Dr Demetrios Patakas, 1 Patriarchou Ioakim Street, Thessaloniki, Greece. terbutaline in asthmatic patients previously treated. with propranolol or pindolol.

\section{Methods}

Eleven asthmatic subjects (four male, seven female were studied after giving informed consent. The sub jects were all adults (mean age in years $31 \pm 8$ SDP with asthma as defined by Scadding $;{ }^{7}$ the mean dura $\rightarrow$ tion of asthma was $7 \pm 3.4$ SD years. All had baseline $\mathrm{FEV}_{1}$ which was less than $70 \%$ of the pre dicted normal value ${ }^{8}$ (mean $45.7 \pm 15 \cdot 1 \mathrm{SD}$ ) and were capable of an improvement in $\mathrm{FEV}_{1}$ of more than $15 \%$ after inhalation of two puffs $(250 \mu \mathrm{g})$ oE terbutaline from a pressurised aerosol. Our patient were having treatment that included terbutaline $2 \cdot 5$ $\mathrm{mg}$ and theophylline $250 \mathrm{mg}$, both four times daily None of the subjects had received corticosteroids of cromoglycate during the 15 days before the study. Bronchodilator drugs were discontinued for 120 hours before each experiment. All subjects were? non-smokers and none had a recent history of uppe $\mathbb{B}$ respiratory tract infection. Seven patients were 
judged to have extrinsic asthma on the basis of a history of atopy or positive reactions to cutaneous testing.

The forced vital capacity (FVC) and its subdivisions were measured with the use of a water-sealed spirometer. Slow vital capacity (VC) and expiratory reserve volume (ERV) were also determined with this spirometer. Thoracic gas volume (TGV) at functional residual capacity (FRC) and airway resistance (Raw) were measured with the use of a variablepressure, constant-volume plethysomograph.910 Residual volume was calculated by subtracting ERV from TGV. Specific airway conductance (sGaw) was calculated by dividing the reciprocopal of Raw by TGV. Total lung capacity (TLC) was calculated by adding FVC or VC (whichever was larger) to residual volume.

Peak expiratory flow rate (PEFR) was measured with a Wright peak flow meter. Maximal expiratory flow volume (MEFV) curves were obtained with the use of a rolling seal spirometer (Ohio 840) after inhalation of air and after seven minutes' inhalation of a helium-oxygen mixture $\left(20 \% \mathrm{O}_{2}\right.$ in $\left.80 \% \mathrm{He}\right)$. The results were recorded on a pen-driven $x-y$ recorder (Hewlett-Packard, model 7041A) with an acceleration of $3000 \mathrm{in} / \mathrm{s}^{2}$ on the $y$ axis and 2000 $\mathrm{in} / \mathrm{s}^{2}$ on the $x$ axis. Volume history was standardised by three inflations to total lung capacity before the performance of all MEFV curves. For both air and $\mathrm{He}-\mathrm{O}_{2}$ subjects performed multiple MEFV manoeuvres until three or more curves with similar slopes and VC within $2 \%$ of each other were obtained. The air and $\mathrm{He}-\mathrm{O}_{2}$ MEFV curves showing the best flow rates were then superimposed at TLC, and from the tracing maximal expiratory flows at $50 \%$ of VC $\left(\dot{V}_{\max }{ }_{50}\right)$ were calculated. From the same manoeuvres $\Delta V \max _{50}$ was also calculated from the formula ${ }^{11}$

$$
\frac{\dot{\mathrm{V}} \max _{50}\left(\mathrm{He}-\mathrm{O}_{2}\right)-\dot{\mathrm{V}} \max _{50} \text { (air) }}{\dot{\mathrm{V}} \max _{50} \text { air }}
$$

The absolute volume of isoflow (Viso- $\dot{v}$ ) was calculated as the quantity between residual volume and the volume at which the $\mathrm{He}-\mathrm{O}_{2}$ and air curves first coincide. ${ }^{12}$ The sum of the absolute Viso- $\dot{v}$ and residual volume was expressed as a percentage of the total lung capacity to obtain the capacity of isoflow (Ciso-v).$^{13}$ Ciso- $\dot{v}$ takes into account changes in both residual volume (which would be expected to increase if obstruction in peripheral airways leading to trapping were made worse by treatment with a beta-blocker) and the volume of isoflow (which would also be increased if equal pressure points moved into small airways as a result of increase of airflow resistance in small airways).
The study was conducted on three separate days at least $\mathbf{4 8}$ hours apart. On the study day the subjects were under medical supervision for 24 hours. Early in the morning subjects underwent a control pulmonary function test consisting of whole-body plethysmography followed by timed spirometry, measurement of PEFR, and construction of maximal expiratory flow-volume curves obtained with subjects breathing air and the $\mathrm{He}-\mathrm{O}_{2}$ mixture. After completing the control studies the subjects were given a coded tablet (double blind) containing placebo, propranolol $40 \mathrm{mg}$, or pindolol $2.5 \mathrm{mg}$. The order of the treatments was randomly distributed. Peak flow rate measurements and standing heart rate counts were made every 30 minutes in the first three hours, and hourly for the following three hours. Pulmonary function tests were repeated two hours after administration of the drug, as peak concentrations in the blood and maximal beta-blockade are known to occur at about this time. Subsequently $0.5 \mathrm{mg}$ of terbutaline was given subcutaneously and 30 minutes later the pulmonary function tests were repeated.

The effect of drug treatment on the density dependence of flow was measured in two ways: (1) as the difference between $\Delta \dot{V} \max _{50}$ measured before (control values) and after beta-blocking treatment and after the administration of terbutaline and expressed as percentage of the control value; (2) as the difference between Ciso- $\dot{v}$ before and after beta-blocking treatment and after administration of terbutaline-this was also expressed as a percentage of the control value. The effect of drug treatment on large airway function was similarly obtained from changes in sGaw and PEFR.

Parametric data were analysed by Student's $t$ test for paired data. A significant difference was assumed to exist for probability values $<0.05$.

\section{Results}

The mean standing pulse rate before the administration of propranolol was $81.2 \pm 5.3$ beats $/ \mathrm{min}$ and it dropped two hours after administration of propranolol to $62.5 \pm 4 \cdot 1 ; 30$ minutes after subcutaneous terbutaline it was $63 \pm 3.9$ beats $/ \mathrm{min}$. The mean standing pulse rate before pindolol was $79 \cdot 5 \pm 4 \cdot 5$ per minute. It decreased after pindolol to $67 \cdot 3 \pm 3 \cdot 8$ beats/min and remained unchanged after subcutaneous terbutaline $(68.0 \pm 4 \cdot 2$ beats $/ \mathrm{min})$. Comparing the changes in heart rate after propranolol and pindolol we found no significant differences.

\section{CONTROL PULMONARY FUNCTION}

There were no statistically significant differences between the placebo, propranolol, and pindolol days 
Table 1 Baseline pulmonary function on the placebo, propranolol, and pindolol days (means $\pm S D$ )

\begin{tabular}{|c|c|c|c|}
\hline & Placebo & Propranolol & Pindolol \\
\hline 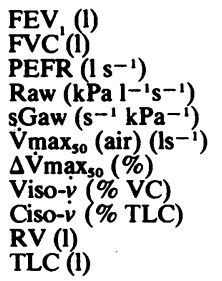 & $\begin{array}{l}1.58 \pm 0.80 \\
2.84 \pm 0.83 \\
4.21 \pm 1.22 \\
0.71 \pm 0.48 \\
0.87 \pm 0.30 \\
0.94 \pm 0.46 \\
39.6 \pm 22 \\
28.1 \pm 18.6 \\
63.2 \pm 14.8 \\
3.24 \pm 1.40 \\
6.08 \pm 1.44\end{array}$ & $\begin{array}{l}1.57 \pm 0.73 \\
2.84 \pm 0.80 \\
4.45 \pm 1.12 \\
0.52 \pm 0.40 \\
1.04 \pm 0.40 \\
1.01 \pm 0.51 \\
35.5 \pm 19 \\
26.8 \pm 11.3 \\
63.3 \pm 11.9 \\
3.01 \pm 1.3 \\
5.86 \pm 1.44\end{array}$ & $\begin{array}{l}1.52 \pm 0.67 \\
2.70 \pm 0.80 \\
4.12 \pm 1 \cdot 16 \\
0.62 \pm 0.49 \\
0.97 \pm 0.30 \\
0.98 \pm 0.49 \\
40 \pm 22 \\
24 \pm 9.5 \\
62.7 \pm 11.9 \\
3.16 \pm 1.5 \\
5.87 \pm 1.44\end{array}$ \\
\hline
\end{tabular}

FEV - forced expiratory volume in one second; FVC - forced vital capacity; PEFR - peak expiratory flow rate; Raw - airway resistance; sGaw - specific airway conductance; $\operatorname{Vmax}_{50}-50 \%$ of slow vital capacity (VC); Viso-viv - absolute volume of isoflow; Ciso-viv - capacity of isoflow; RV - residual volume; TLC - total lung capacity.

in any of the control pulmonary function measurements (table 1); pulmonary function was abnormal on all days. ${ }^{8}$ Raw was increased and tests of expiratory airflow and sGaw were reduced. By comparison with our normal laboratory values of $51.9 \pm 11.8 \%$, mean $\Delta \dot{V} \max _{50}$ was reduced. On the other hand, the volume of isoflow was significantly increased on all study days; our normal values were $13.7 \pm 3 \cdot 1 \%$ VC.

\section{BRONCHOCONSTRICTIVE EFFECT OF PROPRANOLOL AND PINDOLOL}

The changes in the physiological indices after placebo, propranolol, or pindolol are shown in table 2. Changes in Ciso- $\dot{v}$ and $\Delta \dot{V} \max _{50}$ were in opposite directions and there was no quantitative correlation between the two measurements. A reduction in $\Delta \dot{\mathrm{V}} \max _{50}$ indicates bronchoconstriction, while the opposite is true for Ciso- $\dot{v}$. Mean decreases in $\Delta \operatorname{Vmax}_{\text {so }}$ after propranolol and pindolol were significantly greater than those observed with placebo $(p<0.05)$; the mean increase in Ciso- $i v$ was significantly greater with propranolol and pindolol $(p<0.01)$ than with placebo. The mean percentage increase in FRC after propranolol and pindolol was significantly greater than after placebo $(p<0.05$ and $p<0.01$ respectively). We also noticed a significant increase in RV after propranolol ( $p<$ $0.05)$ and pindolol $(\mathrm{p}<0.01)$ by comparison with
the RV changes after placebo.

Mean percentage decreases in SGaw and PEFR after propranolol were significantly greater than the changes observed after placebo $(p<0.001$ and $p<$ 0.001 ). In contrast, pindolol produced no significan decrease in sGaw or PEFR by comparison with placebo. We noted a bronchodilator effect after pin ${ }_{00}^{\circ}$ dolol in one patient, although only the results of tests of large airway function were affected (PEFR and sGaw increased after pindolol by $21 \%$ and $55 \%$ respectively while Ciso- $-\dot{v}$ increased by $28 \%$ an $\Delta \dot{\mathrm{V}} \max _{\text {s0 }}$ decreased by $16 \%$ ).

EFFECT OF TERBUTALINE ON BRONCHOCONSTRICTION INDUCED BY PROPRANOLOL OR PINDOLOI The changes are summarised in table 3 .

The mean percentage increases in sGaw an PEFR were significantly greater $(\mathrm{p}<0.01$ and $\mathrm{p}$ 0.001 respectively) when terbutaline was adminis 0 tered after placebo than after propranolol. The mean percentage increases in SGaw and PEFR werg both significantly greater $(p<0.01)$ when ter. butaline followed placebo than when it followe pindolol.

Ciso- $\dot{v}$ decreased after terbutaline administration and increased when terbutaline was given aftei propranolol or pindolol. These changes were

Table 2 Effect of propranolol and pindolol on results of tests of small and large airways and on lung volumes (values expressed as percentage of control values on day of study)

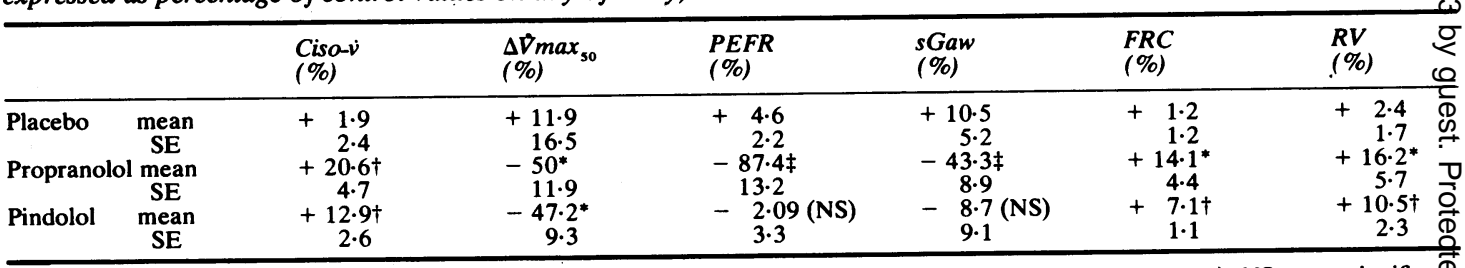

Significantly different from percent change after placebo: ${ }^{*}=p<0.05 ; \dagger=p<0.01 ; \ddagger=p<0.001$ (paired data); NS $=$ not significa FRC - function residual capacity; for other abbreviations see table 1. 


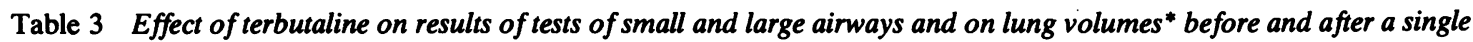
dose of propranolol or pindolol

\begin{tabular}{|c|c|c|c|c|c|c|}
\hline Drug & $\begin{array}{l}\text { Ciso-iv } \\
\text { (\%) }\end{array}$ & $\underset{(\%)}{\Delta \nabla_{\max }}$ & $\begin{array}{l}\text { PEFR } \\
\text { (\%) }\end{array}$ & $\begin{array}{l}\text { sGaw } \\
(\%)\end{array}$ & $\begin{array}{l}F R C \\
(\%)\end{array}$ & $\begin{array}{l}R V \\
(\%)\end{array}$ \\
\hline $\begin{array}{l}\text { Placebo and terbutaline } \\
\text { mean } \\
\text { SE }\end{array}$ & $\begin{array}{r}-12 \cdot 3 \\
4 \cdot 6\end{array}$ & $+\begin{array}{r}148 \\
98 \cdot 1\end{array}$ & $\begin{array}{r}+34.1 \\
5.9\end{array}$ & $\begin{array}{r}+342 \cdot 3 \\
108 \cdot 0\end{array}$ & $\begin{array}{r}-7.9 \\
2.9\end{array}$ & $\begin{array}{r}-11 \cdot 2 \\
4 \cdot 2\end{array}$ \\
\hline $\begin{array}{l}\text { Propranolol and terbutaline } \\
\text { mean } \\
\text { SE }\end{array}$ & $\begin{array}{c}13 \cdot 0 \ddagger \\
4 \cdot 6\end{array}$ & $\begin{array}{l}25 \cdot 8(\mathrm{NS}) \\
23 \cdot 3\end{array}$ & $\begin{array}{r}-10.4 \ddagger \\
3.03\end{array}$ & $\begin{aligned} &- 29.9 \dagger \\
& 10.3\end{aligned}$ & $-\frac{1 \cdot 1}{1 \cdot 3}(\mathrm{NS})$ & $\begin{array}{l}-\quad 2.4(\mathrm{NS}) \\
\end{array}$ \\
\hline $\begin{array}{c}\text { Pindolol and terbutaline } \\
\text { mean } \\
\text { SE }\end{array}$ & $\begin{array}{r}2 \cdot 6^{*} \\
3 \cdot 02\end{array}$ & $-12 \cdot 3(\mathrm{NS})$ & $+\begin{array}{l}5 \cdot 2 \dagger \\
4 \cdot 8\end{array}$ & $\begin{array}{l}57 \dagger \\
+33.4\end{array}$ & $-3.7(\mathrm{NS})$ & $\begin{array}{l}2.2(\mathrm{NS}) \\
3.6\end{array}$ \\
\hline
\end{tabular}

${ }^{*}$ Changes produced expressed as percentage of control values $\left({ }^{*}=p<0.05 ; \dagger=p<0.01 ; \ddagger=p<0.001 ;\right.$ NS $=$ not significant $)$.

For abbreviations see tables 1 and 2.

significant (table 3). The mean percentage changes in $\Delta \operatorname{Vmax}_{50}$ values were not significantly greater when terbutaline followed placebo than when it followed propranolol or pindolol.

An increase in FRC and RV that was produced by the administration of terbutaline after pindolol or propranolol was not significantly different from the FRC and RV changes that occurred when terbutaline was given after placebo.

Although increases in large and small airway resistance were recorded, no patient reported a major change in breathing after taking betablockers.

\section{Discussion}

The standing pulse rate was chosen to assess betablockade since this is influenced more by sympathetic and less by vagal discharge than is the supine pulse rate. ${ }^{14}$ There was a mean decrease of about 19 beats per minute during propranolol treatment and about 12 beats per minute during pindolol treatment; it is difficult to judge whether the difference is due to a relatively higher dosage of propranolol or to the intrinsic sympathetic activity of pindolol. The doses of the drugs were chosen on the basis of accepted beta-blocking potency ratios in man and also because they were close to dosage levels used in clinical practice. ${ }^{15}$

Propranolol reduced sGaw and peak expiratory flow rate significantly but pindolol did not. The significantly greater deterioration in functional indices reflecting changes in large airway calibre after propranolol than after a beta-blocker with high intrinsic sympathetic activity has been referred to by others. ${ }^{316}$ Although the helium isoflow volume and the ratio of MEFR with helium to MEFR with air are very poorly reproducible in normal subjects, ${ }^{17}$ the deterioration in Ciso- $\dot{v}$ and $\Delta \dot{V} \max _{50}$ after pindolol and propranolol in the present study was combined with a significant increse in FRC and RV. This is probably another manifestation of the degree of obstruction within the distal bronchi. Tests of small airway function seem to be required to identify the bronchoconstrictive effect of pindolol in asthmatic subjects.

Terbutaline's bronchodilating effect on large airways was significantly diminished when patients were pretreated with a single dose of propranolol or pindolol. It is difficult to comment on the effect of terbutaline in small airways of patients pretreated with a single dose of propranolol or pindolol since only the Ciso- $\dot{v}$ changes were significant.

Although pindolol has a high intrinsic sympathetic activity and has no detectable effect on the results of tests of large airway obstruction, it has a bronchoconstrictive effect on small airways similar to that of propranolol and thus may not be safe for the asthmatic patient. The bronchodilator action of the $\beta_{2}$-stimulant terbutaline on large airways is diminished after pindolol as well as after propranolol.

\section{References}

i Johnson G, Svedmyr N, Thiringer G. Effects of intravenous propranolol and metoprolol and their interaction with isoprenaline on pulmonary function, heart rate and blood pressure in asthmatics. Eur $J$ Pharmacol 1975;8:175-84.

${ }^{2}$ Thiringer G, Svedmyr N. Interaction of orally administered metoprolol, practolol and propranolol with isoprenaline in asthmatics. Eur $J$ Clin Pharmacol 1976;10:163-82.

${ }^{3}$ McGavin CR, Williams IP. The effects of propranolol and metoprolol on lung function and exercise performance in chronic airway obstruction. $\mathrm{Br} J$ Dis Chest 1978;72:327-32.

${ }^{4}$ Imhof PR. In: Schweizer W, ed. Beta blockers: Present status and future prospects (Symposium). Bern: Huber, 1974:40.

5 Paterson JW. Beta-adrenergic blocking drugs. Br Med J $1971 ; \mathrm{iil}: 652$. 
- Opie LH. Drugs and the heart. Lancet 1980;i:695-8.

${ }^{7}$ Scadding JG. Definition and categorization in bronchial asthma. In: Weiss ED, Segal MS, eds. Bronchial asthma. Boston: Little Brown, 1976:19-31.

${ }^{8}$ Cotes JE. Lung function: assessment and application in medicine. 3rd ed. Oxford: Blackwell Scientific Publications, 1975:386-7.

9 Dubois AB, Botelho B, Comroe JH. A new method for measuring airway resistance in man using a body plethysmograph: values in normal subjects and in patients with respiratory diseases. J Clin Invest 1956;35:327-35.

${ }^{10}$ Briscoe WE, Dubois AB. The relationship between airway resistance, airway conductance and lung volume in subjects of different age and body size. J Clin Invest 1958;37:1279-85.

"Despas P, Leroux M, Macklem PT. Site of airway obstruction in asthmatics as determined measuring maximal expiratory flow by breathing air and helium oxygen mixture. J Clin Invest 1972;51:3235-52.
12 Hutcheon M, Griffin P, Levison $\mathrm{H}$, et al. Volume of $\overrightarrow{\overline{\vec{T}}}$ isoflow: a new test in detection of mild abnormalities $\stackrel{5}{+}$ of lung mechanics. Am Rev Respir Dis므 1974;110:458-65.

13 Tashkin DP, Trevor E, Chopra SK, Taplin GV. Sites of $\overline{\bar{c}}$ airway dilatation in asthma following inhaled versus $\underset{\mathbb{}}{\vec{D}}$ subcutaneous terbutaline. Am J Med 1980;68:14-26.

14 Kofi Ekue JM, Shauks RG, Walash MJ. Observations on the effects of beta-adrenoceptor blocking drug on glyceryl trinitrate tachycardia. Br J Clin Pharmacol. 1974;1:19-26.

15 Declamer PBS, Chatterjee SS, Cruickshank JM, Benson MK, Sterling GM. Beta-blockers and asthma. $\mathrm{Br}$ Heart J 1978;40:184-9.

${ }^{16}$ Conolly ME, Kersting F, Dollery CT. The clinical pharmacology of beta-adrenoreceptor blocking drugs. Prog Cardiovasc Dis 1976;19:203-28.

${ }^{17}$ MacDonald JB, Cole TJ. The flow-volume loop: repro- $-\bar{\circ}$ ducibility of air and helium-based tests in normal subjects. Thorax 1980;35:64-9. 


\section{Notices}

\section{Symposium on death from asthma}

A symposium entitled "Death from Asthma-Can We Prevent It?" that is to be held at East Birmingham Hospital Postgraduate Medical Centre on 13 July 1983 will be of interest to everyone concerned with the management of patients with asthma. The topics will include the recognition of asthma from a clinical and pathological viewpoint, a coroner's impression, lessons from the studies on deaths from asthma, patient education, emergency treatment, and self-referral schemes. Speakers will include Drs Alistair Brewis and Fleming Carswell, Professor Tim Clark, Drs Michael Dunnill, Andrew Johnson, David Stableforth and Charles Stewart, and Mr Andrew Nunn. Further details from Miss MC Wood, Postgraduate Medical Centre, East Birmingham Hospital, Bordesley Green East, Birmingham B9 5ST.

\section{European Working Group for Cystic Fibrosis}

The 12th annual meeting of the European Working Group for Cystic Fibrosis will be held in Athens, Greece, on 3-4 October 1983. This meeting will be preceded on 1-2 October by the annual meeting of the International Cystic Fibrosis (Mucoviscidosis) Association at the same venue. Further information from Ron Tucker, Executive Director, Cystic Fibrosis Research Trust, Alexandra House, 5 Blyth Road, Bromley, Kent BR1 3RS.

\section{Fifth International Congress of Laser Medicine and Surgery}

The Fifth International Congress of Laser Medicine and Surgery, sponsored jointly by Sinai Hospital of Detroit and the International Society of Laser Medicine and Surgery, will be held at the Westin Hotel in Detroit's Renaissance Center from 7 to 9 October 1983, and will include an extensive display of technical and scientific laser exhibits. The subjects to be covered include bronchoscopy and cardiovascular applications. Further information may be obtained from Sinai Hospital of Detroit or from the
Registration Supervisor, Fifth International Congress of Laser Medicine and Surgery, Charles B Slack Inc, 6900 Grove Road, Thorofare, New Jersey 08086, USA.

\section{Dr Alexander Capes Memorial Fund}

Applications are invited from nurses for a grant from the Dr Alexander Capes Memorial Fund to help them enlarge their experience in thoracic nursing. Consideration will be given to applicants from Britain wishing to study at other centres at home or abroad and to overseas applicants who wish to study in Britain and return home afterwards. Applications, giving details of the proposed study, should be sent to the Administrative Secretary, British Thoracic Society, 30 Britten Street, London SW3 6NN, by 16 June. June.

\section{Corrections}

\section{Intrapleural Corynebacterium parvum for malignant pleural efiusions}

In the paper by Drs R Felletti and C Ravazzoni (January p 22) work attributed to Grant ${ }^{12}$ in line 8 of the second paragraph should have been attributed thus: "Millar et al" conducted a comparative trial of intrapleural mustine hydrochloride versus Corynebacterium parvum and showed favourable results with the latter." The reference to Grant applies to a letter about the paper by Miller et al published with a reply from the authors.

Beta-blockers in bronchial asthma: efiect of propranolol and pindolol on large and small airways

In the paper by Dr D Patakas et al which appeared in the February issue (p 108) it was reported in the abstract and in table 2 that PEFR had fallen by $87.4 \% \pm 13 \cdot 2 \%$. This should have been $12 \cdot 6 \% \pm 1 \cdot 6 \%$. 